\title{
Policy Management System: Overview
}

\author{
Hardik Devrangadi ${ }^{1}$, Mohammed \\ Kalender Shihab ${ }^{2}$, Rithwik Goel ${ }^{3,}$ \\ Vishnusai Reddy Tadiparthi ${ }^{4}$ \\ Electronics and Communication \\ Dept. ${ }^{1,3,4}$,Computer Science \\ Dept. ${ }^{2, R}$.V College of \\ Engineering , Bangalore, India
}

hardikd0715@gmail.com¹,kalendershihab@gmail.com²,Rithwik.goel16@gmail.com³,v4sh6@gmail.com

\begin{abstract}
For any insurance contract to see the light of day, a particular process flow is usually followed. This process flow begins with the customer calling an agent to obtain insurance, and ends with the customer receiving a quote for the cover-age. Precision methods focus around improving precision and quality and on planning measures that absolutely address issues and meet the necessary requirements. Unlike automation where the focus is on speeding up tasks and processes, a precision-based approach is centered around improving the quality of the process. More current practices call for ceaselessly examining and retooling tasks/operations to achieve ever more noteworthy business esteem. In this paper, the Insurance Policy Administration System is covered in detail. The format, layout andthe key details that the insurance policy entails is thoroughly covered. Some key functionalities like The Policy Submission, Risk Analysis, Policy changes and renewals, Policy cancellationin a typical Policy Administration System is reviewed. Since the Policy Administration System cannot be a standalone service, and has to be used along with external systems, the integration of this typical policy administration system with an external system like ausermanagementsystemisalsodiscussed.
\end{abstract}

Keywords: Policy Management System, Insurance, Underwriters, Rating, Risk, Client, Contract

\section{INTRODUCTION}

With expanding populace, well-being concerns, mishaps, debacles and pandemics throughout the most recent couple of hundreds of years, Insurance, health \& safety and many other industries expenses and headcount have expanded, however there has not been significant efficiency development in the new years in the insurance sector. With new current center frameworks(moderncoresystems)presently being introduced, numerous cycles are being automated,be coming quicker,more productive and providing protection conveyance. Empowered by present day center frameworks, propertyand casualty insurers are progressively automating their activities. While efficiencies are being understood, the encounters of different enterprises suggest that far more noteworthy expansions in productivity are conceivable. Policy management and under-writing professional experts require automation, unification of unique systems, and the adaptability to serve extraordinaryand consistently changing client requests in an approach organization framework. It should uphold the whole policy lifecycle for individual, business, laborers' remuneration protectionand so forth. It must have automated underwriting and policy management and be planned solely for property/casualty $(\mathrm{P} / \mathrm{C})$ insurers. Additionally, it is a complete system-of-record and center elements of the policy lifecycle including: product definition, underwriting, quoting, binding, endorsements, and reestablishment/renewals with the help of present-day web innovation, in view of industry guidelines, with no heritage code and work out of the box as an independent framework or as a feature of an Insurance Suite and can be coordinated with inheritance frameworks and outsider applications.

For a superior underwriting process, the framework should automate low-level assignments, 
applying the ideal inclination \& abilities at the ideal moments, improving examination, and implementing consistency .With limitless oversight and detectable quality of a record, including value-based history of losses and payments given on tabs of a comparative screen, underwriters can all the more promptly and better evaluate risksandsettleonthecorrectchoice.

\section{Product Background}

An insurance policy is a contract between insured and your insurance company (insurer) - it lays out what's covered, what isn't, and other subtleties of the agreement. It is also called contract of adhesion because the insured and insurer stick to the contract terms. The policy system is where all policies are created, modified and deleted. Basically, it is the centre where all the policies are managed. It gives the insurance company a glimpse of all the policy activities that were performed for a given period of time. The details and specifics for a given policy is handled by the policy system.It is integrated with the billing and claim systems for smooth operations.

\section{Components of a Policy}

Every insurance policy consists of five parts: declarations, insuring agreements, definitions, exclusions and conditions. These days many policies contain a sixth part: endorsements. Each of these have their own importance which is important tounderstand.

\subsection{Declaration Page}

This is also called “dec page” . All the key details about thepolicyarementionedhere.Fore.g.:

1) TheCoveragetype\&nameareprovided

2) Policy subtleties like the approach period, number, and premium.

3) Names of individuals covered and assets (if relevant).

4) The limit on coverages and corresponding deductibles.

5) An elaborate list of endorsements included in thepolicy or their total number.

6) Discounts applicable on the policy .

\subsection{Definitions}

The "Definitions" segment characterizes basic words, limits their implications, and helps avoid ambiguity that could work against the insurer in a court of law. Basic words may have restricted definitions in a specific protection contract. Characterized terms are additionally recorded all through the approach with unique designs like italics, boldface text style, and citations to show they have extraordinary definitions. As a rule, words that aren't characterized are open to interpretation, however characterized ones ought to be carefully reviewed for coverage inclusions andexclusions.

\subsection{Insuring Agreements}

The Insuring Agreements are commonly the fundamental piece of the approach. They characterize who and what is covered by the arrangement and what the backup plan vows to do and not do in return for your premium. This could mean paying for real injury, property harm, and lawful protection costs up to as far as possible in a covered auto crash. You may see an Insuring Agreement recorded as "Strategy Coverage" or another name that demonstrates it's about your inclusion. EveryinclusionpartcouldhaveitsownInsuringAgreement

\subsection{Exclusions and Limitations}

The Exclusions segment commonly follows the Insuring Agreements, and records what your policy doesn't cover. For example, perils like floods and earthquakes in majority of the cases are not covered. Wear and tear are usually not covered in auto policy. Policy may give a part to special cases for rejections, to try not to need to list every conceivable prohibition andinclusions. 


\subsection{Conditions}

The Conditions segment incorporates the policy arrangements that qualify or cut off the insurance agency's guarantee to pay or perform. That implies on the off chance that you don'tmeettheconditionsspreadoverhere;theguarantorcould deny your case. One condition you may find in a homeowner's holder's policy is securing your property after a misfortune to forestall further harm, or permitting the backup plan to review a fire harm guarantee before you start fixes. Some different conditions may identify with subrogation rights, misfortune detailingandsettlement,orabrogationandnon-renewal.

\subsection{Endorsements}

Most approaches additionally contain endorsements. Endorsements are policy shapes that modify the main coverage form. Endorsements can add inclusion or they can alter the inclusion by amending a definition (giving inclusion to non- financial cases). Ultimately, an underwriting can confine or prohibit inclusion, for example, a support that avoids claims from forthcoming and earlier litigation.

\section{Key Users}

The principal users of the application will be policy producers, underwriters, and supervisors . These are individuals inside an insurance agency's arrangement association who are overseeing the policy process consistently.

\subsection{Producers}

Aninsuranceproducerissomebodywhohastheappropriate authorization to sell insurance inside a specific state. Insurance producers sell insurance products on behalf of insurance companies.Alongtheselines, theyshouldhavealotofinformation in their specific insurancesubfield.

\subsection{Underwriters}

Insurance underwriters are experts who assess and break down the dangers implied in safeguarding individuals and resources. Insurance underwriters set up evaluating for acknowledged insurable risks. The term underwriting implies accepting compensation for the readiness to pay for a likely risk. Underwriters utilize particular programming andactuarial informationtodecidetheprobabilityandextentofarisk.

\subsection{Supervisors}

They are the ones who manage the users of the system and approve work done by them . They also look into the policies once they are accepted by both the parties.

\section{Policy Administration Process}

This process defines how a policy flow works and who are key users involved in the process . The elaborate process can be seen in the figure 1.

\subsection{Underwriting}

This process helps insurance companies assess the risk associated with a particular candidate , a group of candidates with same or similar risks. After this they take the decision if the 
insurance company wants to cover these risks. Another motivation behind underwriting is to sort candidates into bunches who present comparable risks. On arranging the choice whether to acknowledge, deny or limit inclusion for each gathering of candidates is taken. This leads to lowering of risk for a particular candidate as all policyholder's pool in . Underwriters are prepared insurance experts who understand risks and how to forestall them. They use ability and data to conclude whether they'll safeguard a person or thing and at whatcost.

1) Reviewinginformationtofindtherisk

2) Determining what sort of policy coverage or what risks the insurance organization consents to protect, andunder whatconditions.

3) Looking to change coverage by endorsement.

4) Searchingforarrangementsthatmaydecreasetherisk in future claims.

\subsection{Rating}

Once underwriting is done, the rating cycle is to allocate costs based on what the insurer trusts it will cost to accept the monetary accountability for the candidate's expected claim. The rate for each group is decided on what amount of claims the insurer is giving for that particular group. Higher the loss for the insurer higher will be the rate. The single most noteworthy impact on the rating cycle is claim recurrence. This doesn't mean how regularly you have made an insurance claim, albeit that will have an additional effect. Claim recurrence estimates how frequently an insured occasion happens inside a gathering comparative with the quantity ofapproaches contained around there . Individuals granting qualities to high- claims gatherings will be charged more for insurance inclusion. All the while individuals who share characteristics with lowcasesgatheringswillbechargedlowerrates.Additionally, insurance organizations offer limits to individuals who show certaincharacteristics.

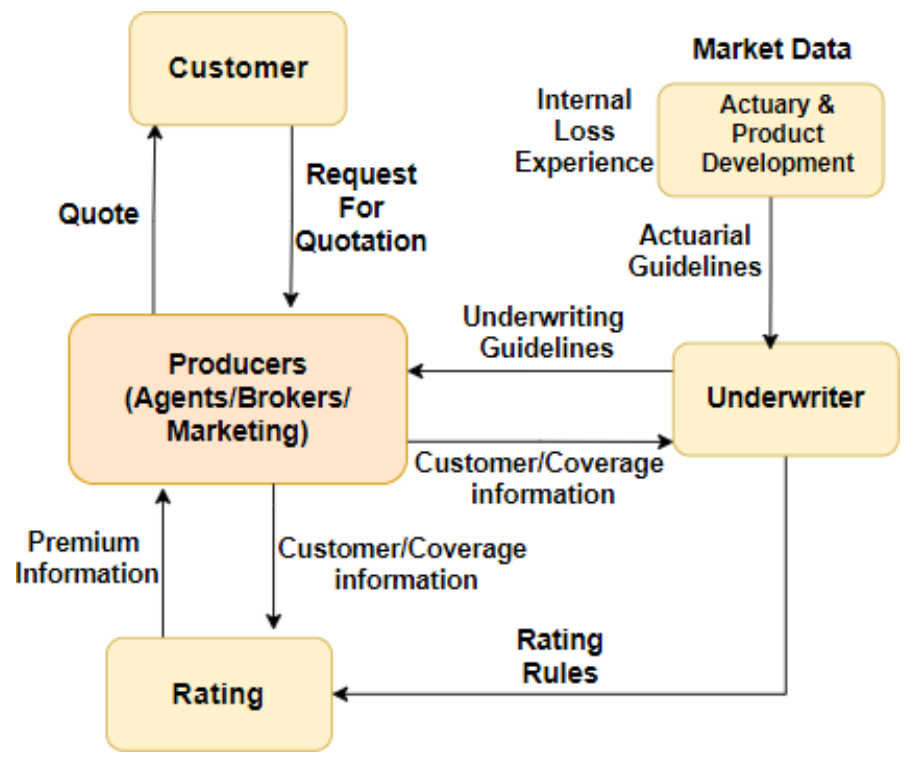

Figure 1. Policy Administration Process

\section{Policy Creation Process}

Policy creation consists of several steps , these begins with a prospect customer (lead). The lead then provides the details and then the quotation is created for the same. If the lead accepts the quotation, he/she becomes a customer. The process canbeseeninthefigure2

1) The first step in issuing a policy is for the potential insured to research the policy that they'd like to gowith. This can be done with the help of a producer, or the potential insured can do their own due diligence.

2) Once a policy plan has been chosen, the next step is to create a policy submission. This is done either by the producer or the employee of the insurance company. The submission involves getting details of the potential insured and fine tuning the small 
details of the policy plans.

3) The final step of submission is the payment of premium. The payment plans and methods are provided to the policysystembythebillingsystem.

4) Once the premium payment is completed, the policy is issued.

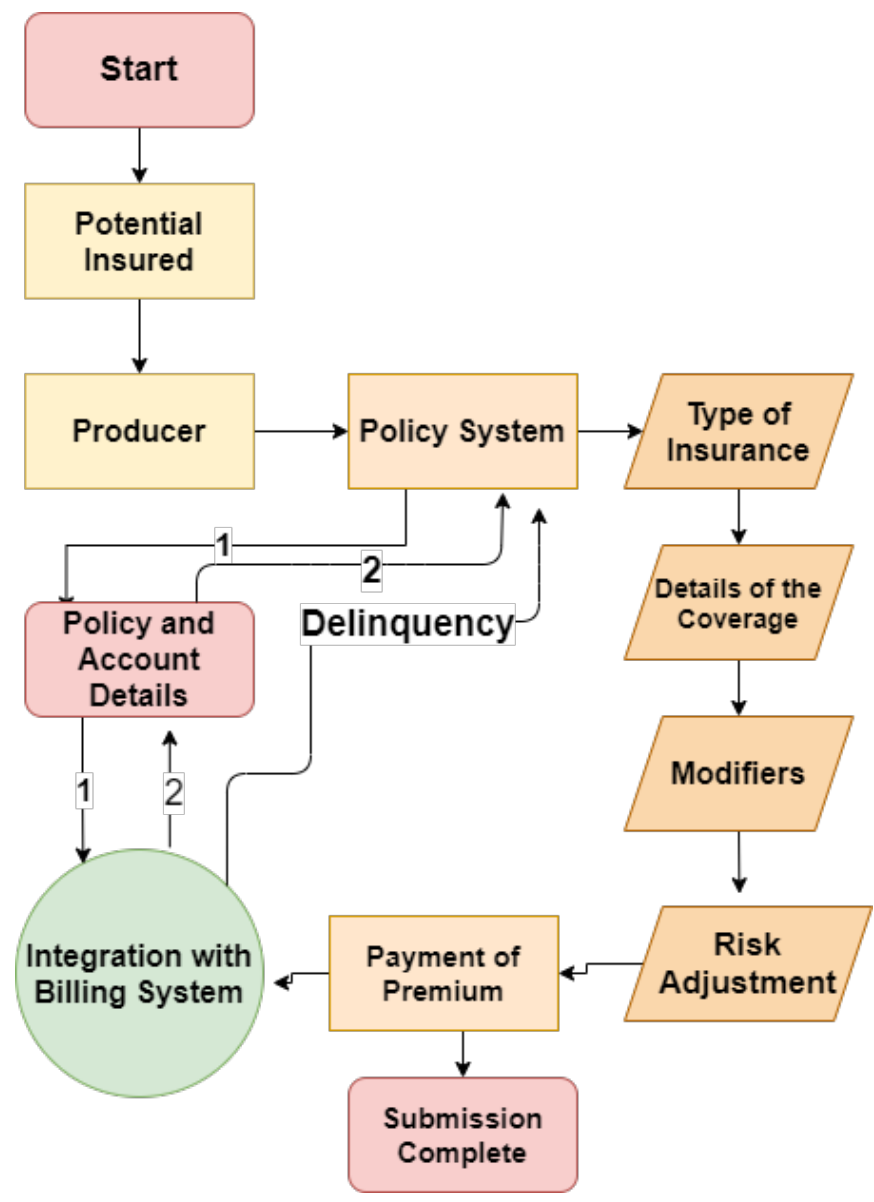

Figure 2. Policy Creation Process

\section{Key Features of a Policy System}

These features are essential for it to be useful for its key users. The main purpose is to make the process very clean and efficient which is ideal for both insurer and insured.

\subsection{Contact's System}

A contacts system saves the details of the insured. The insured type can either be an individual or an organization. A contacts system prevents redundancy when the insured would like a new policy.

\subsection{Producer Management}

This would contain the details of all the producers, theirsub producers, their commission plans and their tiers. The producers can either be individuals or an organization. The policy system can also further have incentive plans for the producers.

\subsection{Insurance Type}

This would contain details of various types of insurance such as commercial liability, inland 
marine etc. and provide fields based on the type of insurance. Further details on the riskcouldalsobeaskedbasedonthetypeofinsurance.

\subsection{Detailed Coverage}

Specifies the total sum insured, the coverage period and any additional coverage that may be required. For example, in the case of commercial property, details such as additional buildings,possessionswithinthepropertycanbeasked.

\subsection{Supplemental Questions and Modifiers}

These are usually used to further optimize the risk and adjust the premium based. For example, in the case of general liability,modifierssuchasdealingwithalcoholcanbeasked.

\subsection{Risk Analysis}

Adjusts the risk further based on factors like location, previous claims and losses. For example, if a customer has a history of many claims, it would indicate that the customer is of high risk. Conversely, if there is no history of previous claims, it would mean that the customer is of low risk. In the cases of a low risk, no claim bonus could also be provided during the next premiumpayment

\subsection{Integration with the Billing System}

This allows for the policy system to display different types of payment plans and payment methods. The billing system would also alert the policy system whenever an insured is due/has missed a premium payment. In case of a non-payment, the billing system can send a delinquency process to the policy system.

\section{Key Benefits}

Change is the solo steady factor in each business under- taking. The insurance industry takes its beating too. It is a highly competitive industry, for any enterprise to survive new products and customers are the only pillars on which it can overcome the competition.

\subsection{Responding to Business Change}

Handling of the policy administration services using a system in a successful way helps in improving and coordinating business measures in a way which can help in accomplishing the drawn-out objectives.

\subsection{Ensure Loyalty of Agents and Clients}

Dealing with the policy management framework benefits aninsurance company by keeping up incredible relations withcustomers and specialists who accept a basic part in businessachievement. This aide the customers during their solicitations and keeping in mind that applying for new approaches.It additionally helps in keeping up consistency across theproduct circulation channels and simplifying everything foragents and making the interaction effective. It helps in makingthings adaptable while managing agents if any issue 
happens.

\subsection{Gaining maximum profits from Current Investment}

By having a solid policy management framework, you can guarantee that all the business speculations are appropriately used to amplify the benefits. Policy organization guarantees thateveryoneofthemeansinthebusinesscyclearecompleted appropriately, accordingly guaranteeing achievement over the longhaul.

\section{Conclusion}

A standardized system can allow for efficient and easy integration of various insurance suite software throughout the entire insurance industry. New core systems can be utilized to improve both the effectiveness and exactness of the whole chain of command as opposed to focusing on the lower levels just where most consideration is paid today. Automating (speeding up processes) in the lower levels lessens operational and support costs such as loss adjustment expense, underwriting expense, and staff time leading to lower costs for manual work . It would also reduce any possibility of errors and improve the underwriting process and the consistency of the entire system. Automation in policy lifecyclemanagement(i.e.: product definition, underwriting, quoting, binding, endorsements, and reestablishment/renewals) has gained a lot of traction in the insurance industry lately and many companies are coming up with products to satisfy the automation and technologyneedsoftheinsuranceproviders.

To conclude, using a well-designed policy system enables the insurance providers to reduce long term cost of ownership andmakesmanagingpoliciesmoreefficient.

\section{REFERENCES}

\subsection{Journal Articles}

[1] G. Shenoy, "Guidewire insurance suite: Claim center - an overview, "International Journal of Advanced Engineering Research and Studies,ISSN:2249-8974, pp. 121-127, 2015.

[2] M. Eling and M. Lehmann, "The impact of digitization on the insurance value chain and the insurability of risks, "The Geneva Papers on Risk and Insurance -Issues and Practice, vol. 43, no. 3, pp. 359-396, 2018.

[3] T. Aven, "Risk assessment and risk management: Review of recent advances on their foundation, "European Journal of Operational Research, vol. 253,no. 1, pp. 1-13,ISSN:0377-2217,2016.

[4] S. Lin, Y.Liu,andY.Xu, "Analysisonmarketsegmentationof the medical insurance and pharmaceutical after the medical insurance reform,” pp. 6545-6548,2011.

[5]Revathi, P., "Technology and Innovation in Insurance - Present and Future Technology in Indian Insurance Industry”, International Journalof Engineering and Management Research, Volume-10, Issue-1, February 2020.

[6] Ms.Babita Yadav, Dr. Anshuja Tiwari,”A Study on factors affecting customers investment towards life insurance policies”, International Journal of Marketing, Financial Services \& Management Research, ISSN 2277 3622, Vol.1 Issue 7, July2012.

[7] Prinja S, Bahuguna P, Gupta I, Chowdhury S, Trivedi M ,"Role of insurance in determining utilization of healthcare and financial risk protectioninIndia”,PLoSONE14(2):e0211793,2019.

[8] R.Vijaya Naik , ”A Study on Structure of Insurance Sector In India”, International Journal of Business and Management Invention (IJBMI) ,Volume 7 Issue 9 Ver. 2,PP—01-08, September 2018.

[9] B.C. Lakshmanna, P. Jayarami Reddy, P. Sravan Kumar, "Operational Efficiency of Selected General Insurance Companies in India”, International Journal of Innovative Technology and Exploring Engineering (IJITEE),ISSN: 2278-3075, Volume-9 Issue-2, December 2019.

[10]Gopu Sowmiya, V. Selvam ,"Drive to digitalization in insurance a study on policyholders' attitude towards using mobile banking’s- 2394- 5125,Vol 7, Issue 9,2020. 